\title{
Pré-melhoramento do camucamuzeiro: estudo de parâmetros genéticos e dissimilaridade ${ }^{I}$
}

\author{
Walnice Maria Oliveira do Nascimento ${ }^{2}$, Fábio de Lima Gurgel², \\ Leonardo Lopes Bhering ${ }^{3}$, Olivia Domingues Ribeiro ${ }^{4}$ \\ http://dx.doi.org/10.1590/0034-737X201461040013
}

\section{RESUMO}

O camucamuzeiro pertence à família Myrtaceae e é espécie em processo de domesticação, encontrada na forma extrativa, a partir de plantas crescendo naturalmente nas margens dos rios e lagos, ou cultivadas em pequenas áreas de terra firme. As estimativas e a compreensão dos parâmetros genéticos desta espécie são importantes para o conhecimento da estrutura genética das populações e para a inferência da diversidade genética presente, além de proporcionar subsídios para predizer os ganhos genéticos e o possível sucesso no programa de melhoramento dessa cultura. Neste sentido, o objetivo deste trabalho foi estimar parâmetros genéticos e a dissimilaridade genética, em acessos existentes no Banco Ativo de Germoplasma de camucamuzeiro, da Embrapa Amazônia Oriental. Para o estudo, foram analisados 46 progênies, colhidos 40 frutos por planta matriz em completo estádio de maturação (frutos com epicarpo totalmente roxo), sendo avaliados sete caracteres morfoagronômicos: peso de fruto (g, PFR), comprimento de fruto (cm, CFR), diâmetro de fruto (cm, DFR), peso da casca (g, PCS), espessura da casca (cm, ECS), número de sementes (n, NSE), peso de sementes (g, PSE). Por meio do Programa Genes, estimaram-se os componentes de variância, herdabilidade e a variabilidade. A importância relativa de caracteres e dissimilaridades entre as progênies, bem como as correlações genéticas entres os caracteres avaliados também foram estudadas. Verificou-se que há dissimilaridade entre os acessos do BAG de camucamuzeiro e que, por causa das correlações significativas entre as variáveis, podem-se adotar métodos de seleção indireta como ferramenta auxiliar no processo de domesticação e melhoramento desta espécie.

Palavras-chave: Myrciaria dubia, fruta nativa, Amazônia, banco de germoplasma.

\section{ABSTRACT}

\section{Pre-breeding of camucamuzeiro: a study of genetic parameters and dissimilarity}

Camu-camu (Myrciaria dubia (H.B.K.) McVaugh) is a shrub of the Myrtaceae family that is under the process of domestication. It is a species used by local populations in Peru and Brazil that exploit the plants occurring naturally on the banks of rivers and lakes or cultivated in small areas of dry land. Estimating and understanding the genetic parameters in this species are important to know the genetic structure of populations, infer on the genetic variability and predict genetic gains and the possible success in the breeding program of this crop. Therefore, the objective of this study was to estimate the genetic parameters and the genetic variability in accessions of Camu camu from GermBank of Embrapa Eastern Amazon. In this study, 46 progenies were analyzed and 40 fully ripe fruits were harvested

Recebido para publicação em 17/05/2013 e aprovado em 26/08/2013.

${ }^{1}$ Instituição de fomento - Projeto melhor FRUTA, Embrapa.

${ }^{2}$ Engenheira-Agrônoma, Doutora. Setor de Propagação de Plantas da Embrapa Amazônia Oriental, Travessa Doutor Enéas Pinheiro, s/n, 66095-100, Belém, Pará, Brasil. walnice.nascimento@embrapa.br (autora para correspondência).

${ }^{3}$ Engenheiro-Agrônomo, Doutor. Setor de Propagação de Plantas da Embrapa Amazônia Oriental, Travessa Doutor Enéas Pinheiro, s/n, 66095-100, Belém, Pará, Brasil. fabio.gurgel@embrapa.br

${ }^{4}$ Engenheiro-Agrônomo, Doutor. Departamento de Genética, Universidade Federal de Viçosa, Campus Viçosa, Avenida Peter Henry Rolfs, s/n, 36570-000, Viçosa, Minas Gerais, Brasil. leonardo.bhering@ufv.br

${ }^{5}$ Engenheira-Agrônoma. Rua Barão de Mamoré, pass. Jambú, 132, Bairro Guamá,66075-051, Belém, Pará, Brasil. oliviadr83@bol.com.br 
per plant (fruits with totally purple epicarp). Seven morpho-agronomic traits were evaluated: fruit weight (g), fruit length $(\mathrm{cm})$, fruit diameter $(\mathrm{cm})$, epicarp weight $(\mathrm{g})$, epicarp thickness $(\mathrm{cm})$, number of seeds $(\mathrm{n})$ and weight of seeds $(\mathrm{g})$. The components of variance, heritability and variability were estimated using the Genes software. The relative importance of traits, the dissimilarities among the accessions, as well as the genetic correlations among the traits were also studied. Genetic variability was found among the accessions of the camu camu GermBank and the significant correlations among the variables indicate that indirect selection methods can be applied to assist in the process of domestication and breeding of this species.

Key words: Myrciaria dubia, native fruit, Amazon, germbank.

\section{INTRODUÇÃO}

O camu-camu (Myrciaria dubia [H.B.K.] McVaugh), pertencente à família Myrtaceae, é espécie em processo de domesticação, usada pelas populações locais do Peru e do Brasil, encontrado na forma extrativa, a partir de plantas crescendo naturalmente nas margens dos rios e lagos, ou cultivadas em pequenas áreas de terra firme (Yuyama, 2011). Apresenta flores hermafroditas, com alta percentagem de polinização cruzada e reduzido nível de autogamia, a que se deve a alta variabilidade fenotípica, tanto qualitativa quanto quantitativa da espécie, apresentando $91 \%$ de alogamia e 9\% de autogamia. Esta espécie apresenta potencial econômico, pelo elevado conteúdo de vitamina C (até $3 \mathrm{~g}$ por $100 \mathrm{~g}$ de polpa) (Rojas et al., 2011). Além disso, contém elevados níveis de cálcio e outros minerais de importância bioquímica.

Graças ao potencial da espécie, na Embrapa Amazônia Oriental (Belém-PA), em 1994, foi implantado o Banco Ativo de Germoplasma (BAG) de Camucamuzeiro e os estudos de caracterização estão sendo realizados, de forma que os seus acessos possam ser caracterizados e, a partir dos melhores genótipos, seja possível quantificar a variabilidade genética dos caracteres em seleção, o valor genético de progenitores e a capacidade específica e heterose manifestada em cruzamentos específicos (Cruz et al., 2012).

Em espécie perene, em fase de pré-melhoramento, como o camucamuzeiro, a estimação de parâmetros genéticos, de acordo com Fehr (1987), possibilita o conhecimento da estrutura genética das populações existentes no BAG e na inferência da variabilidade genética presente, além de proporcionar subsídios para predizer os ganhos genéticos e o possível sucesso do programa de melhoramento dessa cultura. Yuyama (2011) afirma que dados de experimentos com essas bases ainda não existem para o camucamuzeiro. Portanto, é necessário dimensionar as magnitudes das variâncias de origem genética, frente às variações devidas ao ambiente, para que seja possível estimar de maneira adequada o potencial da população, quanto à seleção. Os caracteres fenotípicos de uma popu- lação e os resultantes de cruzamentos dessa população são objetos de estudos dentro de um programa de melhoramento genético, para seleção de materiais superiores.

No caso do camucamuzeiro, os caracteres avaliados como de maior relevância estão relacionados com a produção de frutos que proporcionem o maior rendimento de polpa, utilizada para diversos fins. Graças à alta variabilidade existente nesta espécie, a avaliação do material genético pode fornecer informação referente à resposta genética e ambiental expressada pela planta (Panduro, 2012). A avaliação dos acessos de camucamuzeiro, realizada por meio dos estudos de distância genética, pode fornecer informações a respeito de divergências e relacionar possíveis cruzamentos promissores, separando os acessos em vários subgrupos, de forma que se obtenha homogeneidade dentro e heterogeneidade entre os subgrupos (Cruz e Regazzi, 2012).

Pela análise da importância de caracteres, é possível classificar variáveis, estudadas de acordo com sua contribuição para a diversidade genética, e eliminar aquelas com menor contribuição. $\mathrm{O}$ estudo da diversidade genética entre um conjunto de acessos é feito a partir de informações que, em alguns casos, necessitam da avaliação de muitos caracteres, demandando grande mão de obra e custo. Nesses estudos, é necessário avaliar a importância de cada um deles para a diversidade, identificando-se aqueles que menos contribuem, sendo recomendável seu descarte em estudos futuros.

Por fim, a realização de análises de correlação pode identificar a fração da expressão fenotípica que é de natureza co-herdável. Dessa forma, o conhecimento das correlações genotípicas entre caracteres de acessos de camucamuzeiro é importante informação, no processo de caracterização deste germoplasma e na valoração do Banco Ativo de Germoplasma.

Diante do exposto, o objetivo deste trabalho foi estimar os parâmetros genéticos e a dissimilaridade genética, em acessos do Banco Ativo de Germoplasma de camucamuzeiro, da Embrapa Amazônia Oriental. 


\section{MATERIAL E MÉTODOS}

O Banco Ativo de Germoplasma de Camucamuzeiro, com credenciamento 035/2010-SECEX-CGEN, foi implantado no ano de 1994, e os acessos foram provenientes de coletas realizadas em quatro populações, às margens dos rios Javari e Jandiatuba, afluentes do rio Solimões (AM), e dos rios Trombetas e Tapajós (PA). Está localizado na Embrapa Amazônia Oriental, no município de Belém, PA, com coordenadas geográficas de $48^{\circ} 26^{\prime}$ '45" $\mathrm{O}$ e $1^{\circ} 26^{\prime} 31^{\prime \prime} \mathrm{S}$.

Para o estudo, foram utilizados frutos colhidos de 46 progênies meio-irmãs, sendo 40 frutos por planta matriz, em completo estádio de maturação (frutos com epicarpo totalmente roxo). O delineamento utilizado foi o inteiramente casualizado, em que os tratamentos corresponderam às progênies e, os frutos, às repetições. Foram avaliados sete caracteres morfoagronômicos: peso de fruto (g, PFR), comprimento de fruto ( $\mathrm{cm}, \mathrm{CFR}$ ), diâmetro de fruto (cm, DFR), peso de casca (g, PCS), espessura da casca (cm, ECS), número de sementes (n, NSE), peso de sementes (g, PSE).

Utilizando-se de metodologia descrita em Cruz (2008), por meio do programa GENES, adotaram-se procedimentos multivariados para avaliar a importância de caracteres para estudo da diversidade genética, considerando-se a análise baseada na distância de Mahalanobis, em que a importância relativa dos caracteres foi estimada por meio da participação dos componentes, relativos a cada característica, no total da dissimilaridade observada. A partir desta análise, gerou-se um gráfico de dispersão.

Visando à identificação das progênies para ensaios de competição em diversos ambientes, realizou-se a análise de agrupamento, tendo-se considerado como variáveis, no processo de agrupamento, as estimativas dos valores genotípicos de cada acesso, obtidas para cada caráter em estudo. Realizou-se, inicialmente, com o grupo original de caracteres, o agrupamento, considerando-se a técnica de otimização proposta por Tocher. Novas análises foram realizadas, excluindo-se, passo a passo, dentro do conjunto de variáveis, aquelas de menor importância. Considerou-se uma variável realmente passível de descarte, quando a sua exclusão não alterou o padrão de agrupamento anteriormente obtido. Posteriormente, outra análise de agrupamento foi realizada, desta vez considerando-se o método hierárquico da ligação média, também conhecido como Unweighted pair-group method using arithmetic averages (UPGMA) (Johnson \& Wichern, 2007).

Realizaram-se análises de correlação simples, pela fórmula de Pearson, e análise de correlações parciais entre os caracteres avaliados, para verificar as relações existentes entre eles, e a possibilidade de seleção indireta de algum caráter.

\section{RESULTADOS E DISCUSSÃO}

Por meio do teste F, da ANOVA (Tabela 1), observouse que ocorreu variabilidade genética para os caracteres morfoagronômicos analisados ( $<0.01)$. Gurgel et al. (2012) quantificaram a variabilidade desses caracteres por meio do estudo de parâmetros genéticos, verificando que a variação deve-se mais a causas genéticas do que às ambientais. Os autores observaram, ainda, que todos os caracteres avaliados apresentaram alta herdabilidade, com destaque para PFR $(0,96)$, DFR $(0,96)$ e NSE $(0,95)$. Desta forma, concluíram que, quanto maior a herdabilidade, maior será a contribuição genética para a variabilidade total, o que é desejável em um programa de melhoramento. Por outro lado, Panduro (2012) encontrou níveis moderados de herdabilidade para rendimento de frutos e peso de fruto $(0,26$ e 0,29 , respectivamente).

Segundo Borém \& Viana (2009), o conhecimento da variabilidade fenotípica, resultado da ação conjunta dos efeitos genéticos e de ambiente, é de grande importância para o melhorista, na escolha dos métodos de melhoramento, dos locais para condução dos testes de rendimento e do número de repetições, e na predição dos ganhos de seleção. Obviamente, as variações de ambiente ofuscam as de natureza genética. Por meio da relação $\mathrm{CVg}$ / CVe, é possível identificar os caracteres cuja variação devese mais a causas genéticas do que às ambientais. Quanto mais próximo de 1,0 for esta relação, maior será a variação devida a causas genéticas. Em estudos com camucamuzeiro, Gurgel et al. (2012) observaram que o PFR foi o caráter que mais se destacou $(0,81)$, seguido do $\operatorname{DFR}(0,74)$ e do NSE $(0,67)$.

Observa-se, portanto, a importância do estudo das estimativas de parâmetros genéticos, na etapa de prémelhoramento de uma espécie não domesticada, em que é possível obter parâmetros com elevados coeficientes, que comprovam a variação genética predominante.

O conhecimento da diversidade genética das espécies amazônicas é de grande importância para a domesticação e melhoramento das culturas. Uma das grandes dificuldades, com espécies não domesticadas, como o camucamuzeiro, é a falta de informações sobre a sua variabilidade genética (Rojas et al., 2011).

Observando-se a Tabela 2, pode-se constatar que, pelo agrupamento de Tocher, com base na distância de Mahalanobis das progênies, foram estas distribuídas em oito grupos. Pelo método UPGMA, observou-se a ocorrência de 14 grupos. Por este método, os grupos foram estabelecidos pelo critério local, com o corte sendo realizado a uma distância de 44\%. A utilização de mais de um método para formação de grupos, como apresentado na Tabela 2, é interessante para que possa ser avaliada a consistência do padrão de agrupamento. 
Em um programa de melhoramento, é desejável que se dê prioridade ao cruzamento de materiais que tenham elevada média e apresentem diversidade genética entre si, ou seja, cruzar bons e divergentes, para que se identifiquem materiais bons que se complementem e, desta forma, façam uso da fração não aditiva existente na variância genética. Com os cruzamentos entre acessos de camucamuzeiro, pertencentes a grupos diferentes, podem ser gerados indivíduos, na próxima geração, superiores aos progenitores. Isto ocorre pela combinação entre os alelos que controlam a característica. Após a identificação dos acessos superiores, o cruzamento dialelo será uma forma interessante de descobrir quais são os cruzamentos potenciais, ou seja, aqueles cuja média da próxima geração é maior para todos os caracteres de interesse.

$\mathrm{Na}$ Tabela 3, verifica-se a contribuição relativa dos caracteres avaliados para a diversidade $\left(\mathrm{S}_{\mathrm{j}}\right)$ e os seus valores percentuais, que constituem a medida da importância relativa da variável j para o estudo da diversidade genética. Observa-se que o caráter comprimento de fruto
(CFR) apresentou a menor contribuição, podendo ser recomendada para descarte. Já os caracteres PFR e PCS foram responsáveis por 54,09\% da variação existente dentro dos acessos.

A etapa inicial de qualquer programa de melhoramento refere-se à seleção das populações a serem trabalhadas e esta seleção deve ser fundamentada em testes de acessos, que devem ser avaliados quanto aos caracteres relacionados com o produto de interesse, que, no caso específico do camu-camu, é a produção de polpa para diversos fins. Caso o caráter sugerido seja descartado, recomenda-se observar, nos anos seguintes, se o agrupamento manter-se-á, com base nos caracteres mantidos e análises de repetibilidade.

As estimativas dos coeficientes de correlações de Pearson e Parciais entre pares de combinação entre caracteres, estão apresentadas na Tabela 4. Analisando-se inicialmente os coeficientes de correlação de Pearson, considerando-se uma correlação significativa alta quando o coeficiente obtido entre dois caracteres foi acima de $70 \%$. Verificou-se que, para o caráter PFR,

Tabela 1. Análise de variância agrupada para os caracteres peso de fruto (PFR), comprimento de fruto (CFR), diâmetro de fruto (DFR), peso de casca (PCS), espessura da casca (ECS), número de sementes (NSE), peso de sementes (PSE), em análise de 46 progênies de Myrciaria dubia

\begin{tabular}{|c|c|c|c|c|c|c|c|c|}
\hline \multirow{2}{*}{ FV } & \multirow{2}{*}{ GL } & \multicolumn{7}{|c|}{ QM } \\
\hline & & PFR & CFR & DFR & PCS & ECS & NSE & PSE \\
\hline Tratamentos & 45 & $125,29 * *$ & $1,42 * *$ & $1,62 * *$ & $0,25^{* *}$ & $6,74 * *$ & $2,16^{* *}$ & $4,75^{* *}$ \\
\hline Resíduo & 1794 & 4,65 & 0,12 & 0,71 & 0,02 & 0,69 & 0,11 & 0,39 \\
\hline Total & 1839 & & & & & & & \\
\hline
\end{tabular}

Tabela 2. Formação de grupos pelo método de Tocher e UPGMA, em análise de 46 progênies de Myrciaria dubia

\begin{tabular}{|c|c|c|c|}
\hline \multicolumn{2}{|r|}{ TOCHER } & \multicolumn{2}{|r|}{ UPGMA } \\
\hline GRUPO & ACESSOS & GRUPO & ACESSOS \\
\hline 1 & $\begin{array}{c}22,42,1,23,16,10,31,28,24,40,21,37,8 \\
39,19,2,7,4,11,26,35,45,14,3,6\end{array}$ & 1 & $\begin{array}{l}22,42,23,1,10,24,16,31,7 \\
\quad 40,28,2,21,26,37,19\end{array}$ \\
\hline 2 & $20,43,30,13,34,38,25,27,29$ & 2 & $13,34,30,38$ \\
\hline 3 & $5,41,46$ & 3 & $5,41,6$ \\
\hline 4 & $17,36,15$ & 4 & $20,43,35$ \\
\hline 5 & 18,32 & 5 & $4,11,3,9,14,45,36$ \\
\hline 6 & 12,44 & 6 & $25,33,27,32$ \\
\hline 7 & 9 & 7 & 12,44 \\
\hline 8 & 33 & 8 & 39 \\
\hline 9 & & 9 & 46 \\
\hline 10 & & 10 & 17 \\
\hline 11 & & 11 & 15 \\
\hline 12 & & 12 & 8 \\
\hline 13 & & 13 & 29 \\
\hline 14 & & 14 & 18 \\
\hline
\end{tabular}


Tabela 3. Contribuição relativa dos caracteres para a diversidade baseada na distância generalizada de Mahalanobis, em análise de 46 progênies de Myrciaria dubia

\begin{tabular}{lcc}
\hline Variável & \multicolumn{1}{c}{$\mathbf{S}_{\mathbf{j}}$} & Valor $\mathbf{~ e m ~ \% ~}$ \\
\hline Comprimento de fruto & 133,25 & 3,44 \\
Peso da semente & 181,75 & 4,69 \\
Número de sementes & 376,19 & 9,72 \\
Diâmetro do fruto & 540,52 & 13,96 \\
Espessura da casca & 545,99 & 14,10 \\
Peso da casca & 737,37 & 19,04 \\
Peso do fruto & 1357,20 & 35,05 \\
\hline
\end{tabular}

houve correlação significativa alta a $1 \%$ de significância com CFR $(0,93)$, DFR $(0,97)$, NSE $(0,74)$ e PSE $(0,80)$. Para o caráter CFR, houve maior correlação significativa com DFR $(0,95)$, NSE $(0,69)$ e PSE $(0,71)$. O caráter DFR correlacionou-se significativamente e apresentou altos coeficientes com NSE $(0,71)$ e PSE $(0,78)$. O caráter PCS não apresentou correlação significativa e alta com nenhum outro caráter. Os caracteres ECS e NSE apresentaram correlação alta e significativa com PSE ( 0,72 e 0,75 , respectivamente).

As estimativas de correlações podem ser úteis, quando determinado caráter de interesse é de difícil avaliação. Se esse caráter apresenta correlações fenotípicas e genotípicas significativas com outro de mais fácil acesso, pode-se fazer a seleção indireta com base no caráter de fácil acesso. Quan- do dois caracteres apresentam correlação positiva e significativa, a seleção em um resulta na melhoria do outro. Dificuldades surgem quando dois caracteres apresentam correlação positiva e significativa e um deles é indesejável, ou quando os dois caracteres são desejáveis, mas a correlação é negativa e significativa.

Nos coeficientes de correlação parciais obtidos verificam-se tanto correlações positivas como negativas, havendo níveis de significância a 1 e a $5 \%$. Contudo, não houve nenhuma correlação que pudesse ser considerada alta (acima de 70\%). Os caracteres CFR e ECS não se correlacionaram significativamente com nenhum outro caráter. Já DFR apresentou correlações significativas $(\mathrm{p}<0,01)$ com PFR $(0,69)$ e CFR $(0,57)$. PCS correlacionouse negativamente com PFR $(-0,39, \mathrm{p}<0,05)$. NSE apresentou correlação significativa positiva com $\operatorname{PFR}(0,39, \mathrm{p}<0,05)$ e PCS $(0,77, \mathrm{p}<0,01)$. O PSE apresentou correlação positiva com os caracteres $\operatorname{ECS}(0,52)$, para $\mathrm{p}=1 \%$ e $\operatorname{NSE}(0,38)$, para $\mathrm{p}=5 \%$.

A caracterização morfológica de germoplasma é requisito básico para determinar e quantificar a variabilidade genética presente (Galate et al., 2012). Neste trabalho, verificou-se que há variabilidade entre as progênies do BAG de camucamuzeiro e que, graças às correlações significativas entre as variáveis, podem-se adotar métodos de seleção indireta como ferramenta auxiliar no processo de domesticação e melhoramento desta espécie.

Tabela 4. Coeficientes de correlação de Pearson (triângulo superior) e Parciais (triângulo inferior) para as variáveis peso de fruto (g, PFR), comprimento de fruto (cm, CFR), diâmetro de fruto (cm, DFR), peso de casca (g, PCS), espessura da casca (cm, ECS), número de sementes (n, NSE), peso de sementes (g, PSE) de progênies de Myrciaria dubia do BAG da Embrapa Amazônia Oriental

\begin{tabular}{llllllll}
\hline & PFR & CFR & DFR & PCS & ECS & NSE & PSE \\
\hline PFR & - & $0,93^{* *}$ & $0,97^{* *}$ & $-0,16^{\text {ns }}$ & $0,52^{* *}$ & $0,74^{* *}$ & $0,80^{* *}$ \\
CFR & $0,06^{\text {ns }}$ & - & $0,95^{* *}$ & $-0,14^{\text {ns }}$ & $0,47^{* *}$ & $0,69^{* *}$ & $0,71^{* *}$ \\
DFR & $0,69^{* *}$ & $0,57^{* *}$ & - & $-0,13^{\text {ns }}$ & $0,53^{* *}$ & $0,71^{* *}$ & $0,78^{* *}$ \\
PCS & $-0,39^{*}$ & $-0,16^{\mathrm{ns}}$ & $0,22^{\text {ns }}$ & - & $0,13^{\text {ns }}$ & $0,39^{* *}$ & $-0,02^{\text {ns }}$ \\
ECS & $-0,10^{\text {ns }}$ & $-0,04^{\text {ns }}$ & $0,09^{\text {ns }}$ & $0,11^{\text {ns }}$ & - & $0,58^{* *}$ & $0,72^{* *}$ \\
NSE & $0,39^{*}$ & $0,21^{\text {ns }}$ & $-0,23^{\text {ns }}$ & $0,77^{* *}$ & $-0,01^{\text {ns }}$ & - & $0,75^{* *}$ \\
PSE & $0,13^{\text {ns }}$ & $-0,20^{\text {ns }}$ & $0,13^{\text {ns }}$ & $-0,27^{\text {ns }}$ & $0,52^{* *}$ & $0,38^{*}$ & - \\
\hline
\end{tabular}

**, *. Significativo a 1 e $5 \%$ de probabilidade pelo teste $\mathrm{t}$; ${ }^{\text {ns: }}$ não significativo pelo teste de $\mathrm{t}$.

\section{CONCLUSÕES}

Existe dissimilaridade genética entre as progênies de camucamuzeiro do Banco de Germoplasma da Embrapa Amazônia Oriental para os caracteres de frutos.

A variância fenotípica dos caracteres deveu-se predominantemente a causas genéticas e os caracteres apresentam alta herdabilidade.

Há descritores de natureza co-herdável no BAG, destacando-se o peso (PFR) e o comprimento (PFR) de frutos.

\section{REFERÊNCIAS}

Borém A \& Viana GV (2009) Melhoramento de Plantas. Viçosa, UFV. 529p.

Cruz CD (2008) Programa GENES: diversidade genética. Viçosa, Editora UFV. 278p.

Cruz CD, Regazzi AJ \& Carneiro PCS (2012) Modelos Biométricos Aplicados ao Melhoramento Genético. $4^{\mathrm{a}}$ ed. Viçosa, Editora UFV. 516p.

Fehr WR (1987) Principle of Cultivars Development. New York, Macmillan publishing company. 465p.

Galate RS, Mota MGC, Gaia JMD \& Costa MSS (2012) Caracterização morfo-agronômica de germoplasma de açaizeiro no nordeste paraense. Revista Brasileira de Fruticultura, 34:540-550. 
Gurgel FL, Nascimento WMO, Ribeiro OD \& Bhering LL (2012) Parâmetros genéticos em acessos de camucamuzeiro para caracteres de frutos. In: XXII Congresso Brasileiro de Fruticultura, 2012, Bento Gonçalves. Anais, SBF. CD-ROM.

Johnson RA \& Wichern DW (2007) Applied Multivariate Statistical Analysis. $5^{\text {a }}$ ed. Upper Saddle River, New Jersey, Prentice Hall. 800p.

Panduro MP (2012) Análisis de correlación y heredabilidad em el mejoramiento genético del camu-camu. Scientia Agropecuaria, $1: 23-28$.
Rojas S, Clement Ch. YK \& Nagao EO (2011) Diversidade Genética em acesos do banco de germoplasma de camu-camu (Myrciaria dubia [H.B.K.] McVough) do INPA usando marcadores microssatélites (EST-SSR) Revista Corpoica - Ciencia y Tecnología Agropecuaria, 12:51-64.

Yuyama K (2011) A cultura do camu-camu no Brasil. Revista Brasileira de Fruticultura, 33:335-690. 